\title{
Bambusuril analogs based on alternating glycoluril and xylylene units
}

\author{
Tomáš Lízal and Vladimír Šindeláŕ ${ }^{*}$
}

\author{
Letter \\ Address: \\ Department of Chemistry and RECETOX, Masaryk University, \\ Kamenice 5, 62500 Brno, Czech Republic \\ Email: \\ Vladimír Šindelářr ${ }^{*}$ sindelar@chemi.muni.cz \\ * Corresponding author \\ Keywords: \\ bambusurils; conformers; glycolurils; macrocycles; supramolecular \\ chemistry
}

\author{
Beilstein J. Org. Chem. 2019, 15, 1268-1274. \\ doi:10.3762/bjoc. 15.124 \\ Received: 27 February 2019 \\ Accepted: 29 May 2019 \\ Published: 11 June 2019 \\ This article is part of the thematic issue "Novel macrocycles - and old \\ ones doing new tricks". \\ Guest Editor: W. Jiang
}

(C) 2019 Lízal and Šindelár̆; licensee Beilstein-Institut.

License and terms: see end of document.

\begin{abstract}
The glycoluril monomer is a popular building block in supramolecular chemistry as it is used for the synthesis of versatile host molecules which can interact with cationic, anionic or neutral guest molecules. Here we present the design and synthesis of a new hybrid macrocycle containing glycoluril and aromatic units. The reaction afforded a mixture of macrocyclic homologues from which a two-membered macrocycle was isolated as the main product. Two disastereomers of the macrocycle were separated and characterized by means of NMR spectroscopy and X-ray crystallography. Conformational changes of these diastereomers were investigated using DFT models and variable-temperature NMR.
\end{abstract}

\section{Introduction}

Macrocycles consisting of urea building blocks play an important role in supramolecular chemistry [1]. Urea N-H motifs provide macrocycles with the ability to act as anion receptors due to the stabilizing effect of $\mathrm{N}-\mathrm{H} \cdots$ anion hydrogen bonding [2-4]. Furthermore, the urea groups can participate in intermolecular hydrogen bonding resulting in the formation of tubular [5-7] or gel-like [8] structures. Ureas lacking of N-H hydrogen atoms such as ethyleneureas, glycolurils, and biotin are also important building blocks of macrocyclic receptors such as cucurbiturils [9] and hemicucurbiturils [10].
Bambus[6]urils are a special case of hemicucurbiturils, which comprise six glycoluril units connected by six methylene bridges within their structure $[11,12]$. Due to their hydrophobic cavity with 12 methine hydrogen atoms available for hydrogen bonding, bambus[6]urils bind inorganic anions with high binding affinity and selectivity in both organic media and water $[13,14]$. Previously we used bambusurils to recognize and quantify anions in their complex mixtures at sub-micromolar concentrations by means of NMR [15]. However, sensing of anions by less expensive UV-vis spectroscopy was not possible due to 
the low absorption of bambusurils within the UV-vis region. Therefore, we decided to investigate the synthesis of bambusuril derivatives and analogs containing chromophores in their structure. Initially we tested post-macrocyclic functionalization resulting in bambusurils with chromophore groups on their portals. However, the changes in the absorption spectra of these receptors upon anion binding were negligible since the groups on the portals were too distant from the anion binding site in the center of macrocycle. A different approach for the preparation of UV-vis-active bambusurils is based on the incorporation of the absorbing moiety directly into the macrocyclic framework. In such receptors, anion binding would take place in proximity of the chromophoric part of the macrocycle securing proper functioning of the sensor. Following this line, we decided to investigate the synthesis of bambusuril analogs in which glycoluril and chromophoric units alternate. Here we describe the first results of our efforts.

\section{Results and Discussion}

The preparation of the macrocycles was based on a one-pot reaction of 2,4-dimethylglycoluril and $m$-xylylene dibromide, a structurally simple example of a chromophoric monomer (Scheme 1). The reaction took place under basic conditions using $\mathrm{LiH}$ in dry THF [16]. The $\mathrm{LiClO}_{4}$ salt was used originally as a template in order to drive the reaction towards the three-membered macrocycle $(n=3)$. Later it was found that the salt does not have a significant effect on the distribution of macrocycle homologues probably due to the non-reversible nature of the reaction. However, the salt was used as it facilitated precipitation of the crude product after aqueous work-up. The MALDI analysis (Supporting Information File 1, Figure $\mathrm{S} 1)$ indicated that the reaction yielded a mixture of two $(n=2)$ to five $(n=5)$-membered macrocycles and acyclic oligomers.

The crude mixture of macrocycles was separated by reversedphase flash silica gel chromatography after normal phase silica and size-exclusion chromatography did not show satisfactory results. The separation was achieved using gradient elution with acetonitrile/water mixture. HPLC-MS analysis (Supporting Information File 1, Figure S2) revealed that the main product of the reaction is the two-membered macrocycle $\mathbf{1}(n=2)$ followed by a small amount of the three-membered macrocycle 2 $(n=3)$. The chromatogram (Supporting Information File 1, Figure S2) showed two peaks with the same $\mathrm{m} / \mathrm{z}$ value corresponding to 1 which indicated the presence of two diastereoisomeric forms 1a and $\mathbf{1 b}$ (Figure 1). The isomerism arises from the two possible orientations of glycoluril units within the macrocycle. The rigid structure of glycoluril features methine protons on its convex face which can either point to the same or the opposite direction within the macrocycle. Both isomers 1a and $\mathbf{1 b}$ were present in the crude product also due to the irreversible nature of the macrocyclization reaction. This is in contrast with the common synthesis of bambusuril which employs reversible acidic conditions enabling a transformation of kinetic products to thermodynamic products [12].
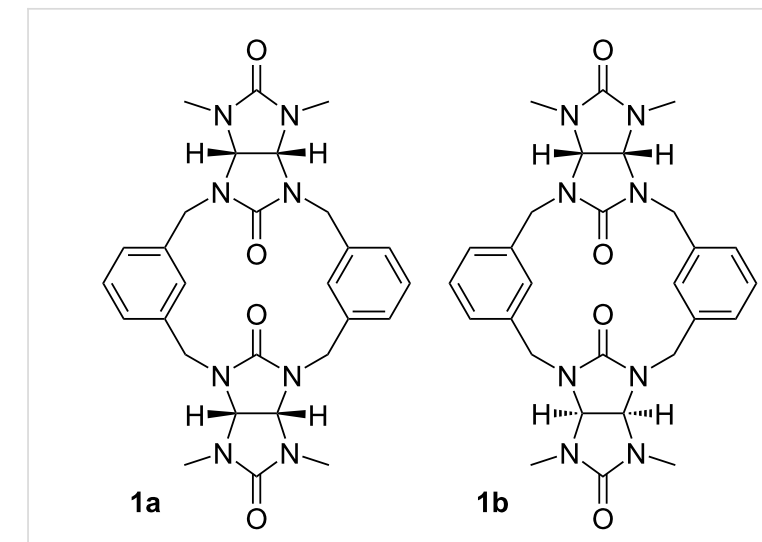

Figure 1: Molecular structures of $1 \mathrm{a}$ and $\mathbf{1 b}$.

Only a small quantity of macrocycle $\mathbf{2}$ in the crude mixture was identified. This minor product should be present in 4 isomeric forms, but we were not able to achieve separation of these isomers. Therefore, our attention turned to macrocycle $\mathbf{1}$, which was the major product of the macrocyclization reaction. The separation of diastereomers $\mathbf{1 a}$ and $\mathbf{1 b}$ was achieved by preparative HPLC using a reversed-phase column and acetonitrile/ water gradient elution. The pure isomers $\mathbf{1 a}$ and $\mathbf{1 b}$ were subjected to chemical-physical analysis.

We first measured ${ }^{1} \mathrm{H}$ NMR spectra of $\mathbf{1 a}$ in $\mathrm{CD}_{3} \mathrm{CN}$ at $30{ }^{\circ} \mathrm{C}$ (Supporting Information File 1, Figure S5), which showed broad signals of glycoluril and aromatic units. Since the

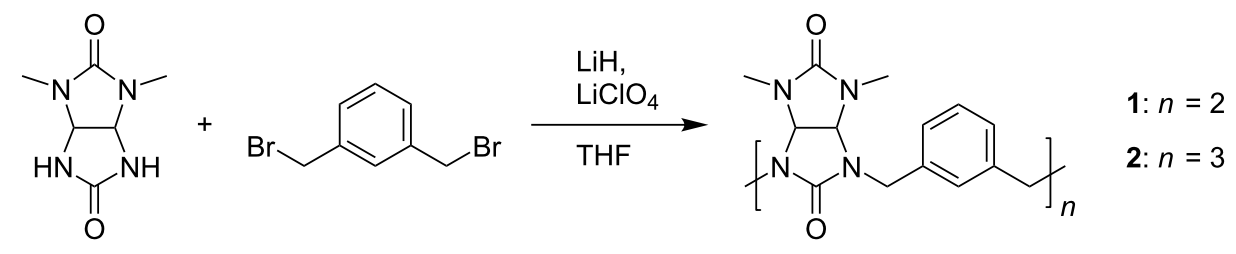


glycoluril units have some degree of flexibility within the macrocycle, we envisioned that the signal broadening is caused by rapid interconversion between several preferred conformers of the macrocycle. The DFT optimization performed at the CAM-B3LYP/6-31G(d) level of theory revealed that 1 a can occur in form of two preferred conformers 1a-1 and 1a-2 (Figure 2).
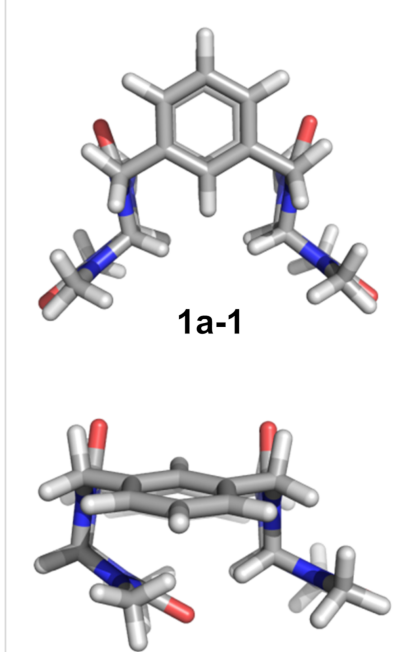

1b-1
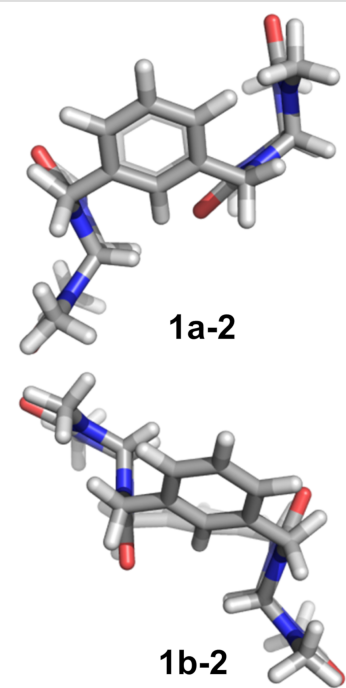

1b-2
Figure 2: Conformers of macrocycles $1 \mathrm{a}, \mathbf{1 b}$ optimized at the CAMB3LYP/6-31G(d) level of theory.
The optimized structures provided us with support to understand the spatial arrangement of the conformers for further NMR studies. While broad signals of 1 a were obtained at $30{ }^{\circ} \mathrm{C}$, lowering of the temperature resulted in sharpening of the signals in the ${ }^{1} \mathrm{H}$ NMR spectra. The spectrum of 1 a measured at $-40{ }^{\circ} \mathrm{C}$ in $\mathrm{CD}_{3} \mathrm{CN}$ showed two sets of signals (Figure 3) which were assigned to the calculated conformers. Conformer 1a-1 possesses a plane of symmetry, therefore, is characterized by single signals of methyl (H6), methine (H5) and aromatic (H1 and $\mathrm{H} 3$ ) protons. Contrary, $\mathbf{1 a - 2}$ is characterized by two signals for each of these protons because of its non-equivalent nature.

The structures of conformers 1a-1 and 1a-2 were further confirmed by 2D NMR experiments. We performed 2D exchange spectrometry (EXSY) NMR experiments to confirm that there is a change of conformation on the NMR timescale [17]. This technique allows to correlate the exchanging signals in both slow and fast exchange regimes. The measured ROESY spectrum featured both NOE interactions of the opposite phase and EXSY peaks of the same phase as diagonal peaks. The EXSY cross-peaks indicate the chemical exchange between methylene protons (H4), the aromatic protons (H1) and methyl protons (H6, Figure 4). The NOE interaction between the glycoluril methine protons (H5) and aromatic proton (H1, Figure 4) also confirmed the assignment of 1a-1. The integration of signals in ${ }^{1} \mathrm{H}$ NMR spectra at $-40{ }^{\circ} \mathrm{C}$ revealed uneven populations of

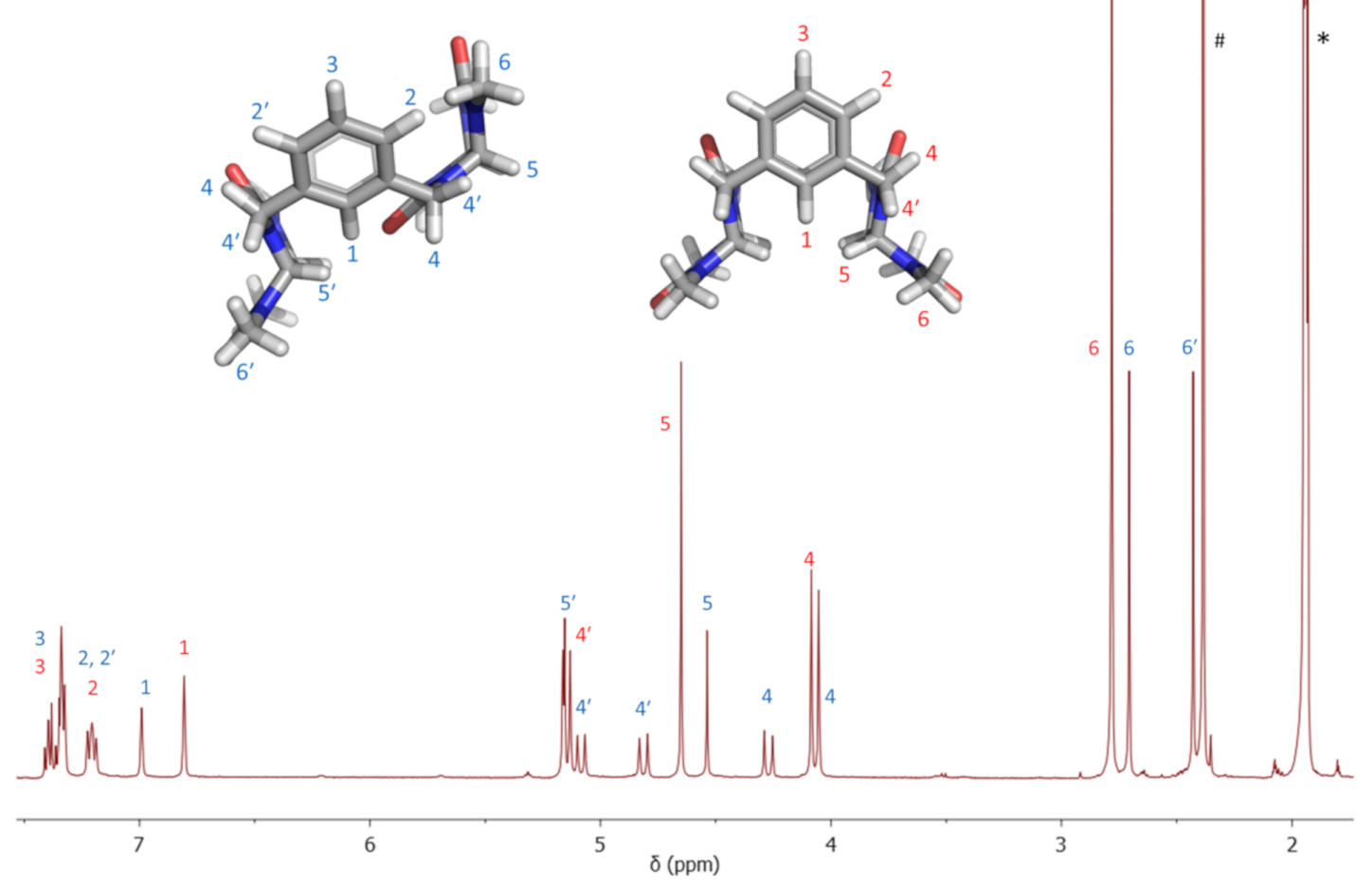

Figure 3: ${ }^{1} \mathrm{H}$ NMR spectrum of $1 \mathrm{a}$ in $\mathrm{MeCN}-d_{3}$ measured at $-40{ }^{\circ} \mathrm{C}$. ${ }^{\#}$ Signal of water. ${ }^{*}$ Signal of acetonitrile. 


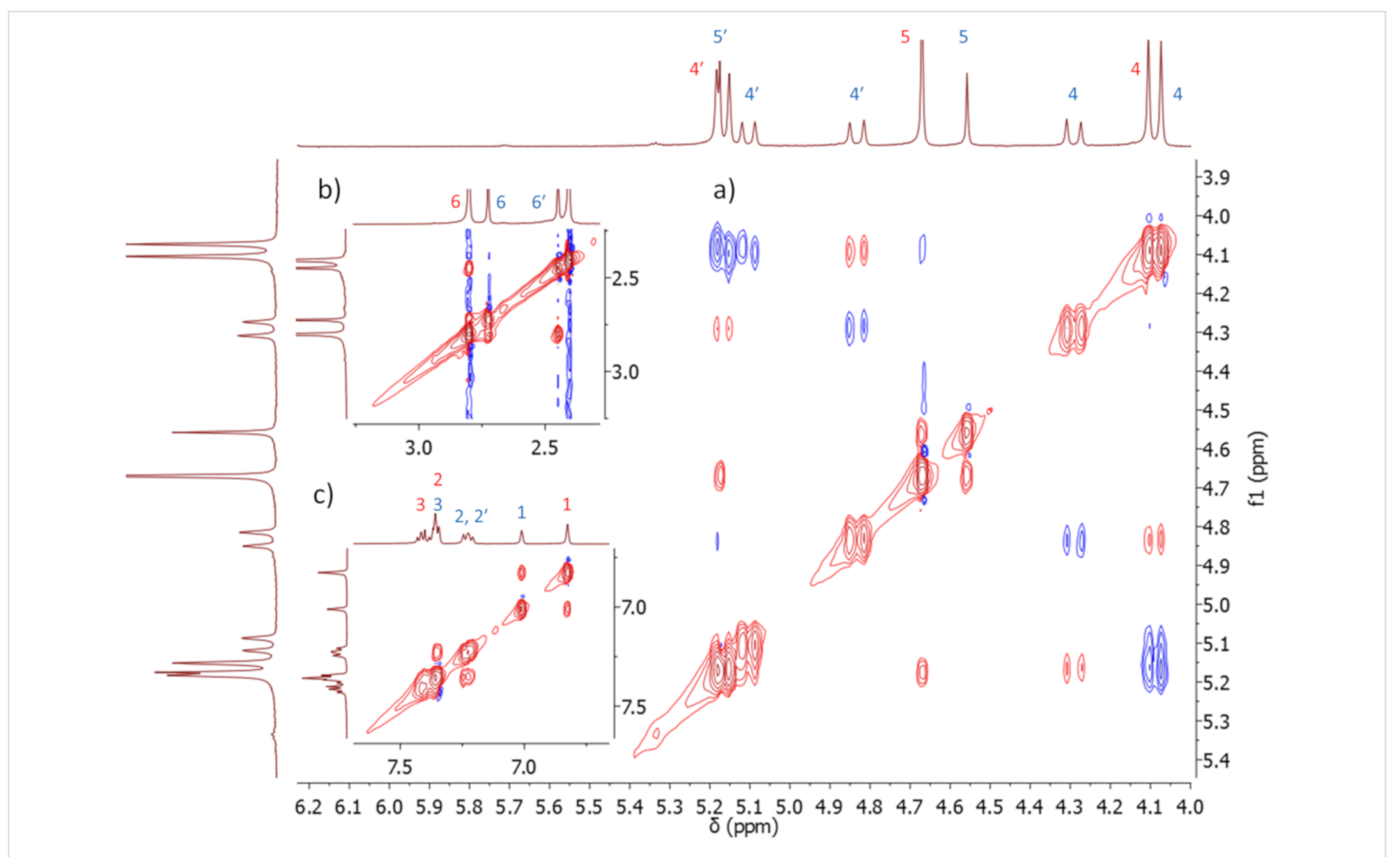

Figure 4: 2D EXSY spectra (ROESY cross-peaks in blue, EXSY cross-peaks in red) measured in MeCN- $d_{3}$ at $-40^{\circ} \mathrm{C}$. a) Zoom of the methylene and methine region, b) zoom of methyl signals, c) zoom of aromatic signals.

conformers in a 4:3 ratio in favor of 1a-1 which remained constant at even lower temperature. By application of the Boltzmann distribution to the conformer population, we have calculated that $\mathbf{1 a - 1}$ is more stable by $0.13 \mathrm{kcal} \mathrm{mol}^{-1}$ than $\mathbf{1 a - 2}$ Conformer 1a-1 is preferred probably due to its higher symmetry.

Diastereomer $\mathbf{1 b}$ was characterized in the same manner as $\mathbf{1 a}$. The molecular modelling showed that $\mathbf{1 b}$ also exists in two forms of conformers $\mathbf{1 b}-\mathbf{1}, \mathbf{1 b}-\mathbf{2}$ differing by the position of the glycoluril units (Figure 2). The NMR spectra (Supporting Information File 1, Figure S9) measured at low temperature featured two sets of signals reflecting the presence of conformers $\mathbf{1 b - 2}$ and 1b-1. However, the ratio of these conformers is $82: 1$ in favor of 1 $\mathbf{1 b - 1}$ which translates to the energy difference of $2.04 \mathrm{kcal} \mathrm{mol}^{-1}$. Stabilization of the $\mathbf{1} \mathbf{b}-\mathbf{1}$ conformer can be attributed to the intramolecular hydrogen bonding interaction between the oxygen atom of one glycoluril unit and methine protons of the second glycoluril unit.

The monocrystals of $\mathbf{1 b}$ suitable for X-ray analysis were obtained upon slow diffusion of diisopropyl ether into the solution of $\mathbf{1 b}$ in dichloromethane and benzene. The X-ray structure features $C_{\mathrm{S}}$ symmetry (Figure 5), which is in good agreement with the structure of the $\mathbf{1 b} \mathbf{- 1}$ conformer calculated by
DFT. The parallel glycoluril units are placed on one side of the plane defined by the xylylene moieties. The macrocycles form a layered structure stabilized by intermolecular hydrogen bonding interaction between the carbonyl oxygens of one molecule and methine and methylene hydrogen atoms of neighboring macrocycles.

Finally, we investigated the affinity of the newly prepared bambusuril analogs $\mathbf{1 a}$ and $\mathbf{1 b}$ towards anions. The addition of halide anions in form of their tetrabutylammonium salts to the solutions of $\mathbf{1 a}$ and $\mathbf{1 b}$ did not induced any change in the NMR spectra of the macrocycles. This indicates that these macrocycles do not bind the studied anions. We assume that the cavity of the macrocycles is too small to be able to include any anions. Indeed the conformer 1b-1 with two facing glycolurils resembles the bambus[4]uril, which also cannot bind anions due to its small cavity [18].

\section{Conclusion}

The reaction between 2,4-dimethylglycoluril and $m$-xylylene dibromide under basic conditions yielded a mixture of macrocycles, from which the major product 1 was isolated. Two diastereomers of the macrocycle, $\mathbf{1 a}$ and $\mathbf{1 b}$, differing in the orientation of one glycoluril unit were obtained. The building blocks within the macrocycles connected via methylene bridges are 

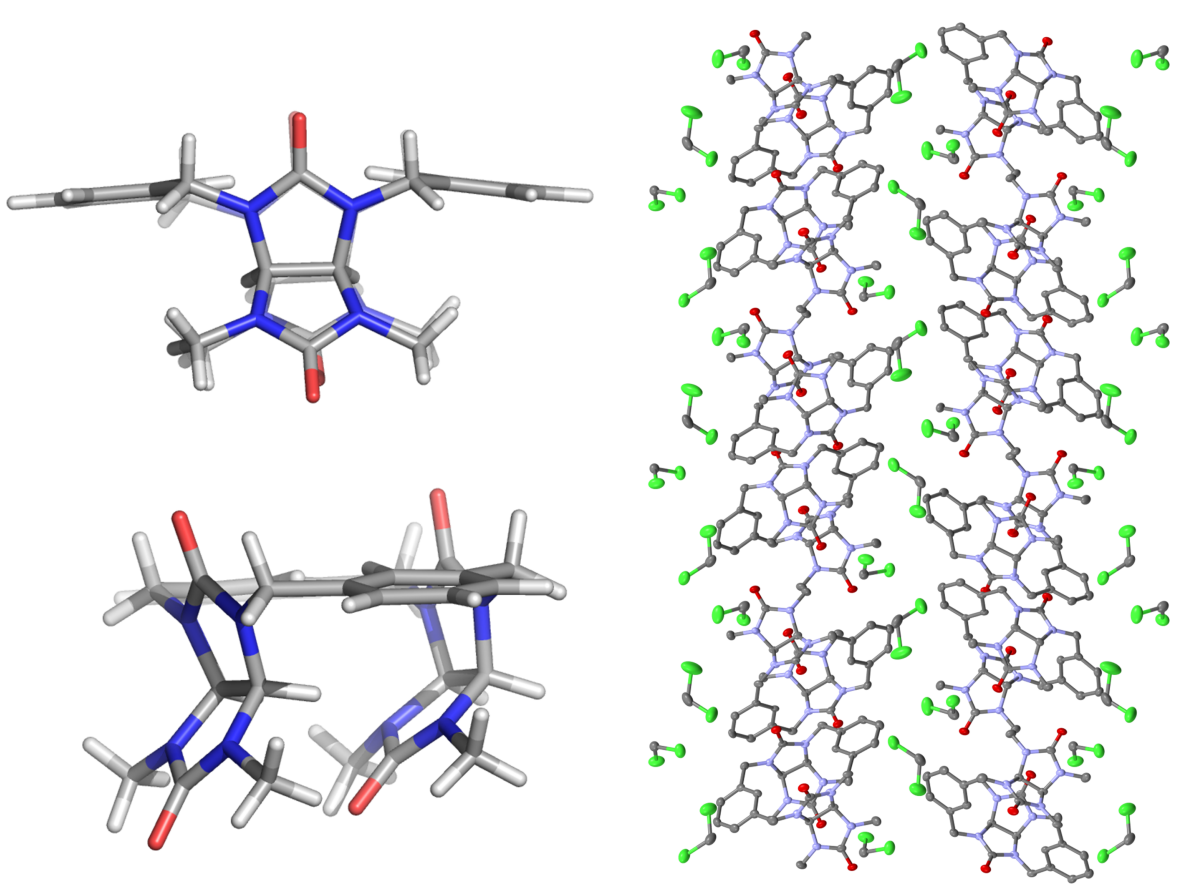

Figure 5: X-ray crystal structure of $\mathbf{1 b}-\mathbf{1}$ (left), layered structure of crystal packing (right).

flexible giving rise to two preferred conformers for each diastereomer. These conformers were identified by molecular modelling and also by low-temperature NMR experiments. Unfortunately, both macrocycles $\mathbf{1 a}$ and $\mathbf{1 b}$ failed to act as an anion receptors due to their small cavities. Therefore, our future experiments will focus on further optimization of the reaction conditions and on the isolation of the three-membered macrocycle suitable for anion binding.

\section{Experimental}

\section{General remarks}

The commercially available starting materials and reagents were used without further purification. 2,4-Dimethylglycoluril was prepared according to a published procedure [11]. ${ }^{1} \mathrm{H}$ and ${ }^{13} \mathrm{C}$ NMR spectra were recorded with a Bruker Avance 500 spectrometer with working frequencies of $500.13 \mathrm{MHz}\left({ }^{1} \mathrm{H}\right)$ and 125.77 $\mathrm{MHz}\left({ }^{13} \mathrm{C}\right)$. The spectrometer was equipped with a BBFO probe. Two-dimensional exchange spectroscopy (EXSY) spectra were recorded with a mixing time of $0.1 \mathrm{~s}$. The experiments were recorded at $233.15 \mathrm{~K}$ unless stated otherwise. Chemical shifts are given in parts per million (ppm) and referenced to solvent residual peaks [19], the coupling constants $(J)$ are reported in hertz $(\mathrm{Hz})$. The multiplicities of signals are reported as singlet (s), doublet (d), triplet (t), multiplet (m). The flash chromatography was performed on a Büchi Reveleris PREP Purification System using RP C18 40g cartridges. Preparative HPLC was done by an Agilent 1260 Infinity using a VP Nucleodur 250/21 C18 HTEC $5 \mu \mathrm{m}$ column. The gradient sepa- ration was achieved for both using HPLC grade $\mathrm{MeCN}$ and milli-Q water. High-resolution mass spectra were recorded by an accurate-mass TOF LC/mass spectrometer using multimode ESI/APCI as an ion source and a manual pump for sampling. Matrix-assisted laser desorption ionization-time-of-flight mass spectra (MALDI-TOF MS) were measured on a MALDI-TOF MS UltrafleXtreme (Bruker Daltonics) and samples were ionized with the aid of a Nd:YAG laser $(355 \mathrm{~nm})$ from $\alpha$-cyano4-hydroxycinnamic acid (HCCA) matrix. Diffraction data were collected at $120 \mathrm{~K}$ on a diffractometer with graphite-monochromated Mo K $\alpha$ radiation.

\section{Macrocycles $\mathbf{1 a}$ and $\mathbf{1 b}$}

2,4-Dimethylglycoluril (1.70 g, $10 \mathrm{mmol})$ and $\mathrm{LiClO}_{4}(1.06 \mathrm{~g}$, $10 \mathrm{mmol})$ were suspended in dry THF $(200 \mathrm{~mL})$ under an Ar atmosphere. After addition of $\mathrm{LiH}(0.47 \mathrm{~g}, 60 \mathrm{mmol})$ the mixture was heated to reflux for 4 hours then cooled to $0{ }^{\circ} \mathrm{C}$. $m$-Xylylene dibromide $(2.65 \mathrm{~g}, 10 \mathrm{mmol})$ was added in three portions. The mixture was stirred at $0{ }^{\circ} \mathrm{C}$ for 2 hours then heated to reflux for 6 days. The reaction was quenched by the addition of $40 \mathrm{~mL}$ of water. THF was evaporated under reduced pressure and precipitated solid material was filtered off. The crude product was dried under vacuum.

The crude product was purified by GRACE flash chromatography using a C-18 reversed-phase cartridge and acetonitrile/ water as mobile phase. The sample ( $350 \mathrm{mg}$ of crude product) was dissolved in DMSO $(400 \mu \mathrm{L})$ and applied to the column. At 
the flow rate of $20 \mathrm{~mL} / \mathrm{min}$ the gradient elution went from $20 \%$ $\mathrm{MeCN}$ to $45 \% \mathrm{MeCN}$ in $30 \mathrm{~min}$, followed by gradient to $100 \%$ $\mathrm{MeCN}$ in $5 \mathrm{~min}$, then continued with $\mathrm{MeCN}$. The macrocycle 1 eluted at $t=12.5 \mathrm{~min}$ in $49 \mathrm{mg}$ yield (14\%).

The diastereomers of 1 were further separated using preparative HPLC. The sample ( $30 \mathrm{mg}$ of $\mathbf{1}$ ) was dissolved in DMSO $(500 \mu \mathrm{L})$ and applied to the column. At the flow rate $40 \mathrm{~mL} / \mathrm{min}$ the gradient elution went from $10 \% \mathrm{MeCN}$ to $70 \% \mathrm{MeCN}$ in $35 \mathrm{~min}$, followed by gradient to $100 \% \mathrm{MeCN}$ in $5 \mathrm{~min}$, then continued with $\mathrm{MeCN}$. The macrocycle 1a eluted at $t=27.2 \mathrm{~min}$, macrocycle $\mathbf{1 b}$ eluted at $t=28.1 \mathrm{~min}$.

1a: ${ }^{1} \mathrm{H}$ NMR (500 MHz, acetonitrile- $\left.d_{3}\right) \delta$ 7.43-7.30 (m, 6H), 7.25-7.17 (m, 4H), $6.99(\mathrm{~s}, 2 \mathrm{H}), 6.81(\mathrm{~s}, 2 \mathrm{H}), 5.16(\mathrm{~s}, 2 \mathrm{H}), 5.15$ $(\mathrm{d}, J=15.7 \mathrm{~Hz}, 4 \mathrm{H}), 5.08(\mathrm{~d}, J=16.0 \mathrm{~Hz}, 2 \mathrm{H}), 4.81(\mathrm{~d}, J=$ $17.7 \mathrm{~Hz}, 2 \mathrm{H}), 4.65$ (s, 4H), 4.54 (s, 2H), 4.27 (d, $J=17.7 \mathrm{~Hz}$, $2 \mathrm{H}), 4.07(\mathrm{~d}, J=15.8 \mathrm{~Hz}, 4 \mathrm{H}+2 \mathrm{H}), 2.78(\mathrm{~s}, 12 \mathrm{H}), 2.71(\mathrm{~s}, 3 \mathrm{H})$, $2.43(\mathrm{~s}, 6 \mathrm{H}) ;{ }^{13} \mathrm{C}$ NMR $\left(126 \mathrm{MHz}\right.$, acetonitrile- $\left.d_{3}\right) \delta 140.25$, 137.91, 137.05, 130.00, 129.39, 128.96, 127.30, 125.98, 124.81, 122.59, 73.31, 68.47, 68.08, 46.95, 45.32, 45.18, 31.19, 31.00, 29.75; HRMS $\left(\mathrm{APCI}^{+}\right) \mathrm{m} / z$ : $[\mathrm{M}+\mathrm{H}]^{+}$calcd for $\mathrm{C}_{28} \mathrm{H}_{32} \mathrm{~N}_{8} \mathrm{O}_{4}$, 545.2619; found, 545.2616.

1b: ${ }^{1} \mathrm{H}$ NMR $\left(500 \mathrm{MHz}\right.$, acetonitrile- $\left.d_{3}\right) \delta 7.37(\mathrm{t}, J=7.5 \mathrm{~Hz}$, 2H), 7.24 (t, $J=7.5 \mathrm{~Hz}, 4 \mathrm{H}), 6.87$ (s, 2H), 5.15 (d, $J=16.6 \mathrm{~Hz}$, $2 \mathrm{H}), 5.10(\mathrm{~d}, J=16.9 \mathrm{~Hz}, 4 \mathrm{H}), 4.58(\mathrm{~s}, 2 \mathrm{H}), 4.15(\mathrm{~d}, J=$ $16.7 \mathrm{~Hz}, 2 \mathrm{H}), 4.10$ (d, $J=16.8 \mathrm{~Hz}, 2 \mathrm{H}), 2.65$ (s, 6H), 2.00 (s, $6 \mathrm{H}) ;{ }^{13} \mathrm{C}$ NMR (126 MHz, acetonitrile- $\left.d_{3}\right) \delta 140.84,136.56$, 129.65, 127.21, 126.72, 123.21, 73.32, 68.34, 45.94, 44.83, $31.15,30.39$; HRMS $\left(\mathrm{APCI}^{+}\right) \mathrm{m} / z:[\mathrm{M}+\mathrm{H}]^{+}$calcd for $\mathrm{C}_{28} \mathrm{H}_{32} \mathrm{~N}_{8} \mathrm{O}_{4}$, 545.2619; found, 545.2618.

\section{Supporting Information}

\section{Supporting Information File 1}

MS and NMR spectra, computational details and crystallographic data for macrocycles $\mathbf{1 a}$ and $\mathbf{1 b}$. [https://www.beilstein-journals.org/bjoc/content/ supplementary/1860-5397-15-124-S1.pdf]

\section{Supporting Information File 2}

CIF data for compound $\mathbf{1 b}-\mathbf{1}$.

[https://www.beilstein-journals.org/bjoc/content/ supplementary/1860-5397-15-124-S2.cif] research infrastructure project LM2015043 funded by MEYS $\mathrm{CR}$ is gratefully acknowledged for the financial support of the measurements at the CF X-ray diffraction and Bio-SAXS and CF Proteomic.

\section{$\mathrm{ORCID}^{\circledR} \mathrm{iDs}$}

Vladimír Šindelář - https://orcid.org/0000-0003-0090-5961

\section{References}

1. Sessler, J. L.; Gale, P. A.; Cho, W.-S. Anion Receptor Chemistry; Monographs in Supramolecular Chemistry; Royal Society of Chemistry: Cambridge, U.K., 2006.

2. Gale, P. A.; Howe, E. N. W.; Wu, X. Chem 2016, 1, 351-422. doi:10.1016/j.chempr.2016.08.004

3. Langton, M. J.; Serpell, C. J.; Beer, P. D. Angew. Chem., Int. Ed. 2016, 55, 1974-1987. doi:10.1002/anie.201506589

4. Blažek Bregović, V.; Basarić, N.; Mlinarić-Majerski, K. Coord. Chem. Rev. 2015, 295, 80-124. doi:10.1016/j.ccr.2015.03.011

5. Shimizu, L. S.; Smith, M. D.; Hughes, A. D.; Shimizu, K. D. Chem. Commun. 2001, 1592-1593. doi:10.1039/b102159c

6. Wu, Z.; Hu, T.; He, L.; Gong, B. Org. Lett. 2012, 14, 2504-2507. doi:10.1021/ol300684j

7. Xing, L.; Ziener, U.; Sutherland, T. C.; Cuccia, L. A. Chem. Commun. 2005, 5751-5753. doi:10.1039/b510118b

8. Prusinowska, N.; Szymkowiak, J.; Kwit, M. J. Org. Chem. 2018, 83, 1167-1175. doi:10.1021/acs.joc.7b02600

9. Lagona, J.; Mukhopadhyay, P.; Chakrabarti, S.; Isaacs, L. Angew. Chem., Int. Ed. 2005, 44, 4844-4870. doi:10.1002/anie.200460675

10. Andersen, N. N.; Lisbjerg, M.; Eriksen, K.; Pittelkow, M. Isr. J. Chem. 2018, 58, 435-448. doi:10.1002/ijch.201700129

11. Svec, J.; Necas, M.; Sindelar, V. Angew. Chem., Int. Ed. 2010, 49, 2378-2381. doi:10.1002/anie.201000420

12. Lizal, T.; Sindelar, V. Isr. J. Chem. 2018, 58, 326-333. doi:10.1002/ijch.201700111

13. Yawer, M. A.; Havel, V.; Sindelar, V. Angew. Chem., Int. Ed. 2015, 54, 276-279. doi:10.1002/anie.201409895

14. Fiala, T.; Sleziakova, K.; Marsalek, K.; Salvadori, K.; Sindelar, V. J. Org. Chem. 2018, 83, 1903-1912. doi:10.1021/acs.joc.7b02846

15. Havel, V.; Yawer, M. A.; Sindelar, V. Chem. Commun. 2015, 51, 4666-4669. doi:10.1039/c4cc10108a

16. Roy, K.; Wang, C.; Smith, M. D.; Pellechia, P. J.; Shimizu, L. S. J. Org. Chem. 2010, 75, 5453-5460. doi:10.1021/jo1009596

17. Sindt, A. J.; Smith, M. D.; Pellechia, P. J.; Shimizu, L. S. Cryst. Growth Des. 2018, 18, 1605-1612. doi:10.1021/acs.cgd.7b01558

18. Havel, V.; Svec, J.; Wimmerova, M.; Dusek, M.; Pojarova, M.; Sindelar, V. Org. Lett. 2011, 13, 4000-4003. doi:10.1021/ol201515c

19. Fulmer, G. R.; Miller, A. J. M.; Sherden, N. H.; Gottlieb, H. E.; Nudelman, A.; Stoltz, B. M.; Bercaw, J. E.; Goldberg, K. I. Organometallics 2010, 29, 2176-2179. doi:10.1021/om100106e

\section{Acknowledgements}

This work was supported by the Czech Science Foundation (18$21801 \mathrm{~S})$, and the RECETOX Research Infrastructure (LM2015051 and CZ.02.1.01/0.0/0.0/16_013/0001761). CIISB 


\section{License and Terms}

This is an Open Access article under the terms of the Creative Commons Attribution License

(http://creativecommons.org/licenses/by/4.0). Please note that the reuse, redistribution and reproduction in particular requires that the authors and source are credited.

The license is subject to the Beilstein Journal of Organic Chemistry terms and conditions:

(https://www.beilstein-journals.org/bjoc)

The definitive version of this article is the electronic one which can be found at:

doi:10.3762/bjoc. 15.124 